\title{
Eco-friendly management of Sitophilus oryzae and Rhyzopertha dominica in stored wheat at Pantnagar, Uttarakhand
}

\author{
Usha Yadav and Ruchira Tiwari* \\ 263145 (Uttarakhand), INDIA \\ *Corresponding author. E-mail: ruchis03@rediffmail.com \\ Received: July 31, 2016; Revised received: December 14, 2016; Accepted: April 13, 2017
}

Department of Entomology, College of Agriculture, G.B. Pant University of Agriculture and Technology, Pantnagar-

\begin{abstract}
The laboratory experiments were conducted to study the efficacy of some indigenous products such as plant products (chopped neem leaves ajwain seed powder, garlic capsules, saw dust), animal derived products ( cow dung cake powder, cow urine) and inert materials ( ash powder, sand, talcum powder, salt) @ 2g/100g of wheat grains against rice weevil, Sitophilus oryzae (Linn.) and lesser grain borer, Rhyzopertha dominica (Fab.) on stored wheat by undertaking various parameters viz., percent adult emergence, percent seed damage, per cent weight loss and per cent germination after six months of storage during April to October 2015. After 180 days of treatments, the minimum number of adults weevils of $S$. oryzae $(4.00,6.00,7.67,9.00,9.67$ and 10.33) were emerged in wheat grains treated with ash powder, sand, cow dung powder, talcum powder, ajwain seed powder and neem leaf powder, respectively with minimum grain damage $(7.33 \%, 8.67 \%, 11.67 \%$ and $12.00 \%)$ was observed on ash powder, sand, ajwain seed powder and talcum powder, respectively, whereas minimum weight loss $(2.67 \%$, $3.67 \%, 5.67 \%$ and $6.67 \%$ ) was recorded on ash powder, sand, cow dung powder, talcum powder and ajwain seed powder, respectively. Similarly, the minimum number of adult beetles of $R$. dominica were emerged $(2.00,2.33$, 6.67,7.00 and 8.33) in ash power, sand, talcum powder, cow dung cake powder and ajwain seed powder, respectively with minimum grain damage $(4.00 \%, 8.00 \% .8 .67 \%$ and $12.67 \%$ and weight loss $(1.33 \%, 4.00 \%, 7.33 \%$ and $11.67 \%$ ) in sand, ash powder, talcum powder and cow dung cake treated wheat grains, respectively. It has been clearly observed that seed germination was not affected adversely in any treatment during six months of storage. The present study clearly revealed that these naturally occurring indigenous products could be used to manage the storage insect pests in wheat.
\end{abstract}

Keywords: Eco-friendly, Indigenous products, Lesser grain borer, Rice weevil, Stored wheat

\section{INTRODUCTION}

Wheat (Triticum aestivum L.) is one of the important cereal crops and major food grains in India. The India is the second largest producer of wheat with total wheat production approx. 96.00 million tons with total area under wheat production is 29.80 million hectares with India's share in global wheat production was recorded 13.2 per cent during 2015-16 (Anonymous, 2016).

The storage of food grain is still a serious problem at farmer's level in many developing countries including India where considerable quantity of grains are damaged by insects and other factors due to inadequate scientific storage facilities and poorly adopted management practices. Insects such as Sitophylus oryzae, Rhyzoperetha dominica, Trogoderma granarium, Corcyra cephalonica, Tribolium casteneum are some of the serious pests of stored food grains cause extensive grain damage costs 13 million tons and 100 million tons due to failure to store properly (Kangade and Zambare, 2013). It has been reported that insects and pests severely infest agricultural stored products and are responsible for worldwide losses of stored grains that are up to 10 to $40 \%$ per annum (Rajashekar, 2010).

Synthetic chemical pesticides have been used for many years to control stored grain pests. These synthetic insecticides cause environmental pollution, toxicity to consumers and residues on grains, pest resistance to pesticide and lethal effects on non target organisms (Subramanyam and Hagstrum,1995). Because of these drawbacks in continued use of conventional insecticides, some alternate eco-friendly substitutes such as plant and animal based bioactive compounds are essentially required for management of stored product pests (Nadra, 2006). Many products of botanical origin such as leaves and seeds of neem and jatropha, garlic capsules have been proved to show insecticidal activity against stored grain insects (Habou et al. 2014 and Onu et al., 2015) as plant extracts have shown ovicidal, repellent, antifeedent and toxic effects in insects (Devi and Devi, 2011). In addition, neem contains Azadirachtin which is a potent antifeedant to 
many insects while salannun and sodium nimbinate are repellent and spermicide, respectively (Isman, 2006 and Shanmugapriyan and Dhanalakshmi, 2015). The organic extracts of plant origin offer protection with minimal impacts on the ecosystem and repel the insect pests from the treated grains by stimulating the olfactory receptors of the insect (Onuet al, 2015. It has been studied that inert dusts such as ash, sand, diatomaceous earth, clay exert their effects through dehydration, adsorption of cuticular lipid or by abrasion (Korunic, 1998) or insects suffocate as film of dust on the insect body inhibits breathing through plugging of the spiracles (Gleen, 1999) .

Increasing public concern over chemical pesticide safety and possible damage to the environment has resulted in increasing attention being given to natural products of mostly plant origin for the control of storage pests, globally Considering the hazardous effects of chemicals used for control of stored insect pest, it is necessitated to use the indigenous eco-friendly approaches such as use of botanicals, inert material and animal origin products for their management under storage conditions (Jadhav, 2009) and (Awasthi and Tiwari, 2012). The present studies were done to assess efficacy of some indigenous products as grain protectants against the rice weevil, Sitophylus oryzae and lesser grain borer, Rhyzoperetha dominica for six months storage period.

\section{MATERIALS AND METHODS}

The experiments were conducted in the Department of Entomology, G.B. Pant University of Agriculture and Technology, Pantnagar, Udham Singh Nagar during April to October 2015. The culture of S.oryzae and $R$. dominicawere obtained from the stock culture prepared on wheat. Plastic containers of $1.5 \mathrm{~kg}$ capacity were used for insect rearing. About $500 \mathrm{gm}$ of grains were kept in each container and about 600 adults of both insects were released separately. They were allowed to lay eggs for 3 to 5 days and removed after 7 days, when the egg laying was over. These containers were kept at room temperature for the adult emergence of $S$. oryzae and $R$. dominica separately.

Extraction of bioactive compounds: The tested plant products i.e. neem leaves (Azadirachta indica (Juss.) and the inert materials i.e. sand, ash powder and saw dust were collected from the University Campus whereas, ajwain powder, talcum powder, salt, garlic capsules were collected from the houses and chemical, coragen were purchased from the local market. The animal waste i.e. cow urine and cow dung and ash were collected from the nearby houses domesticating cows. The neem leaves were washed with water and shade dried to mix with wheat grains in chopped form. The cow dung cake was powdered in pestle and mortar. To prepare the required concentrations of tested indigenous products @2g/100g wheat grains, 20 gram of each powder and $20 \mathrm{ml}$ of cow urine was added separately to $1 \mathrm{~kg}$ of wheat seeds. The dose for chemical, ynaxypyr (Coragen) was $100 \mathrm{mg} / \mathrm{kg}$ of wheat seeds.

Bioassay: About $10 \mathrm{~kg}$ seeds of UP-2338 variety of wheat was collected from Department of Genetics and Plant Breeding, College of Agriculture, G.B. Pant University of Agriculture and Technology, Pantnagar, Uttarakhand, India. The moisture content of seeds was less than $12.0 \%$. The required quantity of test materials@2g/100g were mixed with 250g sterilized and conditioned wheat seeds separately. The seeds were taken in the polythene bags and shaken with hands horizontally and vertically so that every grain can have a thin coating of test products. The treated grains were stored in the plastic boxes having lids and considered as a grain lot fortaking out requisite amount of grains for further studies. An aliquot of $20 \mathrm{~g}$ grain for each treatment was drawn separately after every 30, 60, 90 and 180 days of application of test materials, kept in plastic vials $(10 \times 2.5 \mathrm{~cm})$, and replicated thrice for each candidate product for the both tested insects, separately. Five pairs of freshly emerged adults of weevils were released in each glass vial. The vials were covered with perforated lids. Forty days after their release, total number of adults (F1 adult emergence) emerged in each treatment were counted till the last emergence of the adults and emerged adults were discarded from the vials containing treatments. The observations were also recorded on per cent grain damage and weight loss. The grain damage by one generation of the pest was recorded on the basis of the visual count. Weight loss was recorded by the exclusion of frass from the grain and was compared with the weight loss in untreated control.

The per cent grain damage and weight loss were calculated by using formulae given below:

\begin{tabular}{|c|c|c|}
\hline \multirow{2}{*}{$\begin{array}{l}\text { Per cent } \\
\text { grain dam- } \\
\text { age }=\end{array}$} & $\begin{array}{c}\text { Number of damaged } \\
\text { grains }\end{array}$ & \multirow{2}{*}{$\times 100 \ldots \ldots \ldots$} \\
\hline & $\begin{array}{c}\text { Total number of } \\
\text { grains }\end{array}$ & \\
\hline $\begin{array}{l}\text { Per cent } \\
\text { weight loss }\end{array}$ & $\begin{array}{c}\text { Initial weight of } \\
\text { grain - Final weight } \\
\text { of grains }\end{array}$ & $\times 100 \ldots \ldots 2$ \\
\hline$=$ & $\begin{array}{l}\text { Initial weight of } \\
\text { grains }\end{array}$ & \\
\hline
\end{tabular}

This method of bioassay (Kumavat, 2009) was repeated after 30, 60, 90 and 180 days of application of treatments and F1 adult emergence, per cent grain damage and weight loss was assessed to find out the efficacy of tested indigenous products against storage insects, $S$. oryzae and $R$. dominica.

Test for germinability: To observe the adverse effect of different tested products on wheat seeds, 
germination test of the treated seeds was carried out separately at 30,60,90 and 180 days interval of seed treatment by taking 15 wheat seeds in triplicate. The seed germination tests was carried out employing rolled paper towel test according to International Rules of Seed Testing (Anonymous,1985). The germinated seeds were counted after 4-6 days.

Statistical analysis: The per cent data on grain damage, weight loss and germination was transferred into angular values and number of insects emerged into $\sqrt{ } \mathrm{X}+1$ values for analysis of variance.

\section{RESULTS AND DISCUSSION}

Effect of different eco-friendly products on Sitophilus oryzae in stored wheat: The effect of different tested indigenous products i.e. chopped neem leaves, ajwain seed powder, garlic capsules, cow urine, cow dung cake powder, ash powder, talcum powder, sand, saw dust and salt on adult emergence, seed damage and weight loss of wheat grains caused by S.oryzae after $30,60,90$ and 180 days of treatment is given in Table 1.

Adult emergence (F1) progeny: All tested indigenous products were found highly effective along with insecticide, Rynaxypyr (coragen) against F1 adult population of S.oryzae after 30 days and 60 days of treatments as no adult emergence was observed in ash powder, ajwain seed powder, ash powder, talcum powder, sand and coragen with minimum number of adults emerged in ajwain seed powder (0.33) followed by talcum powder (2.67), chopped neem leaves (3.00) after 60 days of grain treatment. A significantly less mean number of adults were recorded after 90 days of treatment in sand (1.33) followed by ash powder (2.67), talcum powder (5.67) with maximum population of adult weevils were observed in untreated grains (36.00). After six months of treatments, mean number of $S$. Oryzae adults was again found significantly minimum $(2.67,3.336 .00,7.67,9.00$ and 9.67 ) in ash powder, coragen, sand, cow dung powder, talcum powder and ajwain seed powder, respectively. These present studies supported the findings of (Hakbij, 2002) tested cow dung ash as an insecticide against $S$. granarius and Tribolium castaneum larvae as ash kills insects by dessication or by filling the inter granular spaces, restricting insect movement and emergence. Similarly, results obtained in present study was in conformity with results obtained by Ali et al., 2009 reported the efficacy of indigenous materials such as sand and neem leaf powder against $S$. oryzae, T. casteneum and grain moth, Sitotrogacerealella in stored wheat. Upadhyay and Ahmad, 2011 reported the efficacy of essential oil extracted from ajwain plant, Carumcopticum against eggs, larvae and adults of rice weevil, S. oryzae.

Grain damage: The data regarding the grain damage due to F1 progeny of S.oryzae in treated wheat grains is shown in Table-1. No any grain damage was found in ash powder sand and coragen after 30 and 60 days of treatments with significantly minimum grain damage was recorded in ajwain seed powder $(0.33 \%)$ followed by talcum powder $(2.67 \%$ ) and chopped neem leaves (3.00) in comparison to untreated control (23.33\%) after 60 days of treatments. Similarly, the per cent grain damage after 90 days of treatment showed significant minimum grain damage in ash powder $(3.33 \%)$ which was at par with sand $(3.67 \%)$ with maximum damage found in untreated grains $(51.67 \%)$. The per cent grain damage after 180 days of treatments showed significantly very less grain damagein cow dung ash powder (7.33 $\%)$ and sand $(8.67 \%)$ whereas among other products, grain damage was ranged from (11.67\%) in ajwain seed powder to $(24.67 \%)$ in salt with maximum damaged grains found in untreated wheat $(62.33 \%)$.

The effect of sand in form a layer of 2 and $3 \mathrm{~cm}$ over the grain of bengal gram, Cicer arietinum, which was found most effective with regard to poor oviposition emergence, development and less damage to seed of bengal gram ( Chaudhury and Mahla, 2001). (Kabir, 2003), found that neem leaf powder and sand showed some efficacy in protecting mung bean against Callosobruchuschinensis L. in storage.

Weight loss: The data obtained on weight los due to F1 adult generation is presented in Table 1. No weight loss was recorded in ash powder, ajwain seed powder, sand and coragen treated grains after 30 and 60 days days of treatments with very less weight loss of ) treated wheat grains recorded in ajwain seed powder $(0.33$ $\%$ ) and talcum powder $(1.67 \%)$, whereas in other treatments it was ranged from $2.67 \%$ to $8.33 \%$ in cow dung cake powder and cow urine respectively, in comparison to untreated grains $(18.67 \%)$. A significantly negligible weight loss of grains was observed in ash powder $(1.33 \%)$, coragen $(2.00 \%)$, sand $(2.33 \%)$ and ajwain seed powder $(2.33 \%)$ after 90 days of treatments with significantly minimum weight loss of $2.67 \%$ in ash powder and $3.67 \%$ in sand treated wheat grains with maximum weight loss was observed in untreated grains $(49.00 \%)$ after 180 days of treatments. The practice of mixing inert materials such as sand, saw dust, talc, ash and plant products with seeds of cereals to save them from stored pests is quite common in rural areas of India ( Rajapakse, 2006). The efficacy of plant and animal origin products against $S$. oryzae was studied by (Arya and Tiwari , 2013) with no adverse effect on quality parameters of wheat seeds after 180 days of storage period. Mishra and Pandey (2014) reported the efficacy of neem oil, neem cake, dry neem leaf powder and neem seed kernel powder as seed protectant against $S$. oryzae in stored wheat after 3, 6 and 9 months of storage.

Effect of different eco-friendly products on Rhyzapertha dominica in stored wheat: The data on the efficacy of different eco-friendly products on $R$. 
Usha Yadav and Ruchira Yadav / J. Appl. \& Nat. Sci. 9 (2): 736 - 743 (2017)

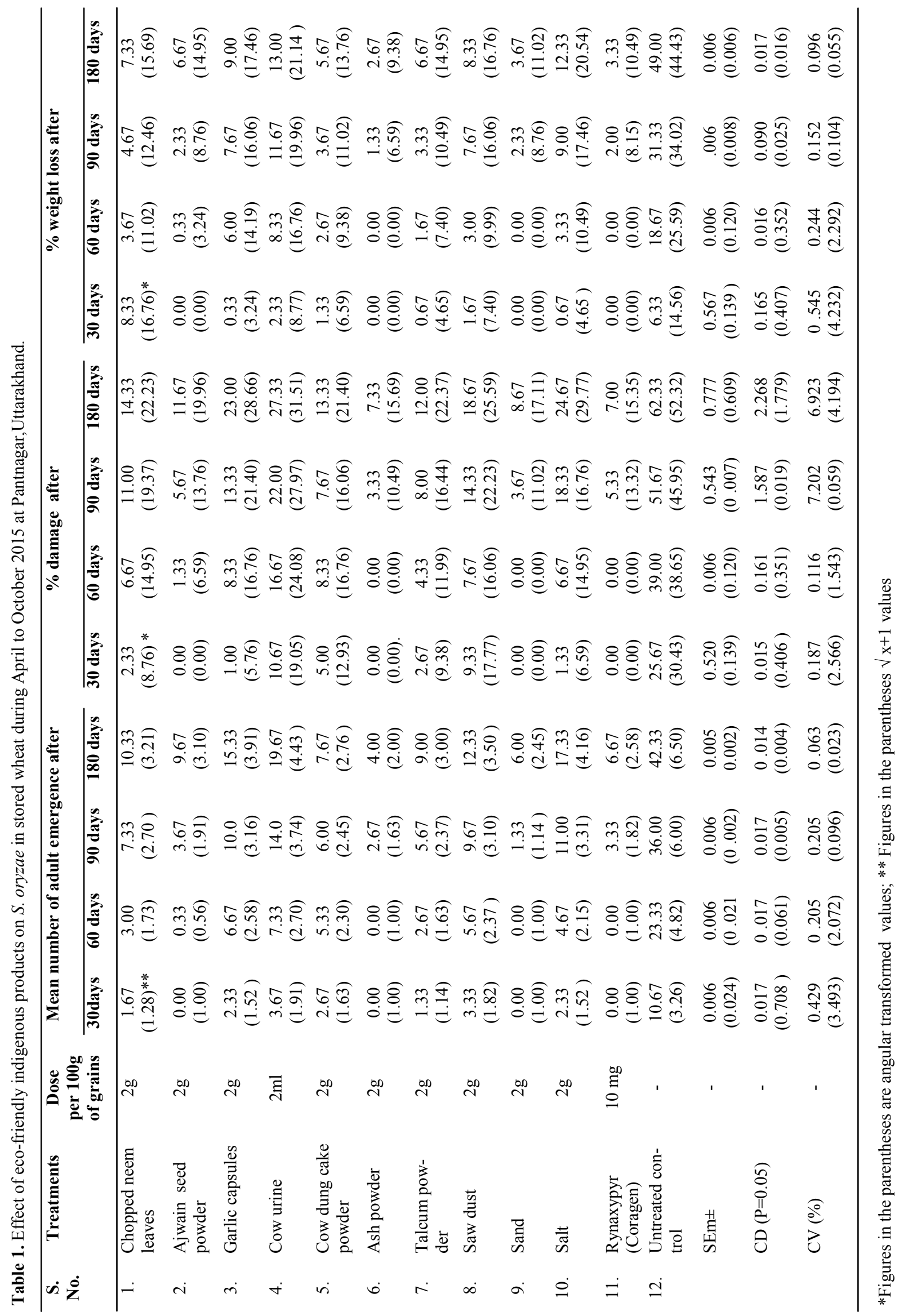


Usha Yadav and Ruchira Yadav / J. Appl. \& Nat. Sci. 9 (2): 736 - 743 (2017)

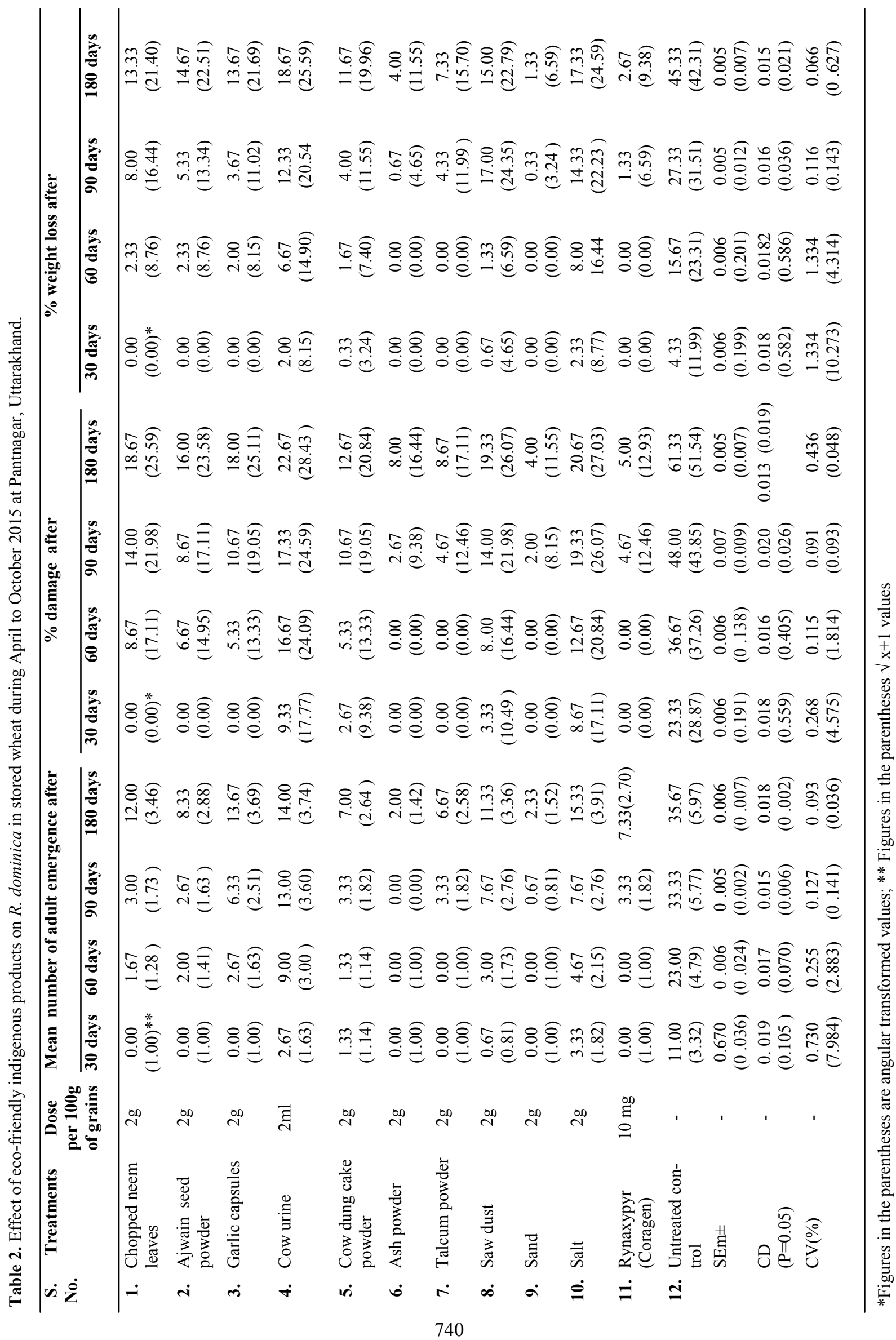


Usha Yadav and Ruchira Yadav / J. Appl. \& Nat. Sci.9 (2): 736 - 743 (2017)

Table 3. Effect of eco-friendly indigenous products on germination of wheat seeds during six months storage period from April to October 2015 at Pantnagar, Uttarakhand.

\begin{tabular}{llllcll}
\hline $\begin{array}{l}\text { S. } \\
\text { no. }\end{array}$ & Treatments & $\begin{array}{l}\text { Dose } \\
\text { per 100g } \\
\text { of grains }\end{array}$ & After 30 days & After 60 days & After 90 days & After 180 days \\
\cline { 5 - 6 } & & $2 \mathrm{~g}$ & $100.00(90.00)^{*}$ & $97.78(82.28)$ & $91.11(73.34)$ & $88.89(69.35)$ \\
\hline 1 & Chopped Neem leaves & $2 \mathrm{~g}$ & $100.00(90.00)$ & $100.00(90.00)$ & $95.56(76.53)$ & $91.11(73.34)$ \\
2 & Ajwain seed powder & $2 \mathrm{~g}$ & $100.00(90.00)$ & $100.00(90.00)$ & $97.78(82.28)$ & $93.33(73.93)$ \\
3 & Garlic capsules & $2 \mathrm{~g}$ & $100.00(90.00)$ & $97.78(82.28)$ & $91.11(73.34)$ & $84.44(66.76)$ \\
4 & Cow urine & $2 \mathrm{ml}$ & $97.78(82.28)$ & $97.78(82.28)$ & $88.89(69.35)$ & $86.67(69.44)$ \\
5 & Cow dung cake powder & $2 \mathrm{~g}$ & $93.33(73.93)$ & $91.11(73.34)$ & $86.67(69.44)$ & $82.22(64.57)$ \\
6 & Ash powder & $2 \mathrm{~g}$ & $97.78(82.28)$ & $95.56(76.53)$ & $88.89(69.35)$ & $82.22(64.57)$ \\
7 & Talcum powder & $2 \mathrm{~g}$ & $95.56(76.53)$ & $93.33(73.93)$ & $91.11(73.34)$ & $88.89(69.35)$ \\
8 & Saw dust & $2 \mathrm{~g}$ & $91.11(73.34)$ & $91.11(73.34)$ & $84.44(66.76)$ & $82.22(64.57)$ \\
9 & Sand & $2 \mathrm{~g}$ & $97.78(82.28)$ & $93.33(73.93)$ & $88.89(69.35)$ & $86.67(66.44)$ \\
10 & Salt & $10 \mathrm{mg}$ & $97.78(82.28)$ & $95.56(76.53)$ & $93.33(73.93)$ & $84.44(66.76)$ \\
11 & Rynaxypyr (Coragen) & & $95.56(76.53)$ & $91.11(73.34)$ & $86.67(69.44)$ & $77.78(61.42)$ \\
12 & Untreated control & - & $0.601(1.609)$ & $0.567(1.003)$ & $0.519(0.654)$ & $0.553(0.502)$ \\
& Sem \pm & & $1.756(4.692)$ & $1.655(2.928)$ & $1.516(1.910)$ & $1.616(1.466)$ \\
& Cd ( P=0.05) & & $1.078(3.454)$ & $1.031(2.227)$ & $0.994(1.578)$ & $1.119(1.292)$ \\
\hline
\end{tabular}

* Figures in parenthesis are angular transformed value.

dominica with respect to adult emergence, seed damage and weight loss after30, 60, 90 and 180 days of treatment is given in Table 2.

Mean number of adult emergence in (F1) progeny: After 30 days of treatments, all tested indigenous products were found highly effective along with insecticide, coragen against $\mathrm{F} 1$ progeny of $R$. dominica as no adult emergence was observed in chopped neem leaves, ash powder, talc powder, garlic capsules, ajwain seed powder sand whereas very less mean adult emergence was found in cow dung cake powder (1.33) followed by chopped neem leaves (1.67), ajwain powder (2.00), garlic capsules ( 2.67), saw dust (3.00) with no adult emergence in ash powder, talcum powder, sand and coragen after 60 days of grain treatments. Similarly, significantly less mean number of adults were recorded after 90 days of treatment in sand (0.67), ash powder (1.00) and ajwain seed powder (2.67). After 180 days of treatment, again ash powder, sand, talcum powder, cow dung powder and ajwain seed powder were found effective with significantly very less mean number of adult emergence (2.00), (2.33), (6.67), (7.00) and ( 8.33), respectively with maximum population of adult beetles were recorded in untreated wheat grains (35.67).

The effectiveness of neem leaf powder and ash from various sources against different stored grain pests has been shown by (Achiano et al., 1999). The neem leaves had repellant effect as well as direct toxicity for F1 progeny emergence and grain infestation by $R$. dominica (Amin et al., 2000). The effect of extracts of neem and garlic on $R$. dominica was reported by Singh

et al., 1996 which showed the lower fecundity per female, adult emergence, increased insect mortality and reduced grain damage. The neem leaf powder suppressed the progeny emergence of $R$. dominica even at lower dose $(1.5 \%)$ and completely protected the seeds from its damage (Samyal and Sharma, 2006)

Grain damage: The effect of indigenous products on grain damage caused by F1 progeny of $R$. dominica is shown in Table 2 and no any grain damage was found in talcum powder, ash powdr, chopped neem leaves, ajwain seed powder, garlic capsules, sand and coragen with significanly less grain damage was recorded in cow dung cake powder and garlic capsules $(5.33 \%$ each) followed by ajwain seed powder $(6.67 \%)$ after 60 days of treatments. Similarly, very less grain damage was observed after 90 days of treatment in sand (2.00) and ash powder (2.67) treated wheat grains. The data regarding the per cent grain damage after 180 days of treatments clearly showed the efficacy of indigenous products with significantly very less grain damage was recorded in inert materials mixed with wheat grains i.e. sand $(4.00 \%)$, ash powder $(8.00 \%)$, talcum powder $(8.67 \%)$ in comparison to damage obtained in untreated grains $(61.33 \%)$.

Synthetic dusts are effective in controlling pests of stored pulses and cereals and are used commercially in developed countries (Golob, 1997). The different inert dusts viz, fly ash, cow dung cake ash, rice husk ash, diatomaceous earth @ $5 \mathrm{~g} / \mathrm{kg}$ seed were found effective against major storage insect pest infestating wheat seed (Kadam et al., 2012). An inert dust, 
diatomaceous earth was found very effective as wheat grain protectants against stored grain insects, i.e.,S.oryzae, R.domininca and T. confusum with their complete mortality (El-Sayed et al.,2010, Mahgoub and Mawaheb, (2014).

Weight loss: The data obtained on weight loss caused by $\mathrm{F} 1$ adult generation of $R$. dominica after 30 days to 180 days of treatments is presented in (Table 2). The data clearly showed no weight loss of grains in chopped neem leaves, ajwain seed powder, garlic capsules, ash powder, talcum powder, sand and coragen after 30 days and 60 days of treatments whereas, significantly negligible weight loss of grains was observed in sand $(0.33 \%)$ and ash powder ( $0.67 \%)$ after 90 days of treatments showed the efficacy of these inert materials against $R$. dominica. After 180 days of treatments, among the tested indigenous products, significantly vey less grain weight loss 1.33 $\%, 4.00 \%$ and $7.33 \%$ was observed in sand, ash powder and talcum powder, respectively, whereas in other products the weight loss was ranged from 11.67 $\%$ in cow dung cake powder to $18.67 \%$ in cow urine with maximum weight loss obtained in untreated grains $(45.33 \%)$.

An eco-friendly management of R.dominica on stored wheat was done by using neem and dharek @ 2.0\% and found the minimum adult emerged, grain damage and weight loss with no adverse effects of these plant products on viability of the wheat seeds (Kakde, 2014).

Effect of eco-friendly products on wheat germination: To observe the adverse effect of different indigenous products on the quality of wheat seeds, germination test of the treated seeds was carried out separately at $30,60,90$ and 180 days of treatments of wheat grains. The data regarding the effect of eco-friendly indigenous products on germination of wheat seeds is presented in Table 3 indicated that under the experimental conditions, the indigenous products did not impair seed germination and the grains retain their viability even after six months of storage. After 30 days of treatments of grain the germination was found $100 \%$ in cow urine, chopped neem leaves, ajwain seed powder and garlic capsules treated seeds with $97.78 \%$ germination in cow dung cake powder, talcum powder and salt treated grains whereas in rest of the treatments germination was ranged from $91.11 \%$ in sand to 95.56 $\%$ in saw dust treated and untreated wheat grains. After 60 days of treatment, the germination was again found $100 \%$ in ajwain seed powder and garlic treated wheat seeds while in other treatments it was ranged from $97.78 \%$ in cow urine, cow dung cake powder to $91.11 \%$ in ash powder and sand treated wheat seeds. The seed germination was ranged from $84.44 \%$ in sand to $97.78 \%$ in garlic capsules after 90 days of treatments while the seed germination was recorded between $82.22 \%$ in talcum powder, ash powder and sand to 93.33 in garlic capsules treated grains with lowest seed germination was found in untreated control $(77.78 \%)$ after six months of storage. The present findings are in conformity with results obtained by (Verma et al., 1983), who observed no adverse effect on the seed viability on seeds treated with neem, castor and mustard oil.Kumavat et al., 2009 reported that neem products mixed with wheat grains showed no adult emergence of $R$. dominica with very less grain damage and weight loss up to 90 and 270 days of storage with no adverse effect of test compounds on seed germination of wheat.

\section{Conclusion}

The present study clearly revealed that the inert materials such as sand, talc powder, ash powder along with plant products ajwain seed powder, chopped neem leaves and garlic capsules were found most effective followed by animal derived products i.e. cow dung cake powder and cow urine against adult emergence of both tested storage insects viz. $S$ oryzae and $R$. dominica significantly very less grain damage and weight loss of treated wheat grains after 30, 60, 90 and 180 days of treatments. Similarly, there was no any adverse effect of application of these naturally occurring indigenous products on germination of wheat seeds up to six months of storage period. Considering the hazardous effects of chemicals used for control of stored insect pests, it is necessitated to use the eco-friendly approaches such asinert materials, botanicals and animal origin products for their management. It is a novel approach to use animal waste products i.e. cow urine and cow dung cake powder and ajwain seed powder as a grain protectants against $S$. oryzae and $R$. dominica on wheat. Thus, it may be concluded that, the these plant and animal derived products and inert materials can play an important role in protection of wheat from insect invasion during storage as in comparison to synthetic insecticides, all tested indigenous products are cost effective, eco-friendly and easily available which can easily be used by the small scale farmers for the eco-friendly management of storage insect pests and as seed protectants upto six months of storage period.

\section{ACKNOWLEDGEMENTS}

Thanks are due to ICAR funded All India Coordinated Research Project on Wheat and Barley for providing funds for the above research work. We extend thanks to Director Experimentation Station, Dean Agriculture and Head, Department of Entomology, College of Agriculture, Govind Ballabh Pant University of Agriculture and Technology, Pantnagar for providing necessary facilities for these investigations.

\section{REFERENCES}

Achiano, K. A., Giliomee, J. H. and Pringle, K. L. (1999). 
The use of ash from Aloe marlothii or control of maize weevil, Sitophilus zeamisin stored maize. African Entomol., 7(1):169- 172

Ali, M. Y., Latif, M. A. and Ali, M. 2009. Effect of some containers, chemicals and indigenous materials on incidence of wheat pests in storage. J. Ag. Rural dev., 7 (1\&2): 107-113

Amin, M. R., Shahjahan M., El- Taj H. F., Iqbal, T .M. T. and Hussain M. A. (2000). Use of akenda, biskatli and neem leaves at botanical insecticide against lesser grain borer. Bang. J. Entomol., 10(1-2):1-13

Anonymous (1985). International rules for seed testing. Seed Sci. Technol., 13: 307-320

Anonymous (2016). Annual Report. Indian Institute of Wheat and Barley Research. Karnal, Haryana, 5-6

Arya, M. and Tiwari, R. (2013). Efficacy of some indigenous bioproducts against rice weevil, Sitophilus oryzae (Linn.) on wheat. Ind. J. App. Res., 3 (6):13-15

Awasthi, M. and Tiwari, R. (2012). Effect of neem leaf, jatropha seed powders and cow urine on the growth and development of rice moth, Corcyra cephalonica (St.) in stored wheat. Ind. J. App. Res., 26(1): 63-67

Chaudhury, S. D. and Mahla, J. C. (2001). Insect pests infesting stored wheat in different climatic region of Haryana. Crop Res. Hissar., 2(3): 384-386

Devi, K. C. and Devi, S. S. (2011). Insecticidal and oviposition deterrent properties of some spices against coleopteran beetle, Sitophilus oryzae. J. Food Sci. and Technol., 10: 1007-1011

El- Sayed Ferial, A., El-Zun H. M., Abd El-latif A. M. and Nasr M. E. H. (2010). Insecticidal effect of some inert dusts against three of stored grain insects at Kafrelsheikh Governorate. J. Pl. Prod. Pathol., 1 (12): 959 972

Gleen, D. M., Puterka, G. J., Vanderzwet, T., Beyers, R. E. and Feldhake, C. (1999). Hydrophobic particle film: a new paradigm for suppression of arthropod pest and plant diseases. J. Eco. Entomol., 92: 759-771

Golob, P. (1997). Current status and future perspective for inert dusts for control of stored product insect. J. Stored Prod. Res., (33):69-79

Habou, Z. A. Haoudhi, A., Basso, A., Adam, T., Haubruge, E. and Verheggen, F. J. (2014). Insecticidal effect of Jatropha curcas L. seed oil on Callosobruchus maculates Fab. and Bruchidiusatrolineatus Pic (Coleoptera: Bruchidae) on stored cow pea seeds (Vignaunguiiculata L. Walp.) in Niger. African J. Ag. Res., 9(32): 2504-2510

Hakbij, T. (2002). The traditional historical and prehistorical use of ashes as an insecticide with an experimental efficacy of washed ash, Env. Archaeol., (7): 13-22

Isman, M. B., Koul, O., Luczyneki, A., Kaminski, J. (1990). Insecticidal and antifeedant bioactivities of neem oil and their relationship to Azadirachtin content. J. Agri. Food and Chem., 38: 1406-1411

Jadhav, S. (2009). Relative toxicity of certain plant extracts against Corcyra cephalonica under laboratory condition. J. Appl. Biosci., 35: 89-90

Kabir, K., Raman, M. and Ahmed, M. S. (2003). Utilization of different containers, chemicals and indigenous materials for the management for the management of pulse beetle (CallosobruchuschinensisL.) in storage. Annual Report, Entomology Division, Bangladesh Agricultural Research Institute, Joydebpur, Gazipur $67-$
71

Kadam, U. K., Palande, P. R., Shelarandg, V. R. and Bansode, M. (2012). Efficacy of inert dusts as grain protectants against Rhyzoperthadominica infesting stored wheat. International J. Fores. Crop Improv., 3 (2) :134-136

Kakde, S. P., Dhonde, S. V., Sarda, A. L., Khillare, P. W. and Deshwal, H. L. ( 2014) Screening of wheat varieties and eco-friendly management of Rhyzoperthadominica (Fab.) on wheat. Pl. Arch., 14(1): 431-437

Kangade Y. P. and Zambare S. P. (2013). Effect of Extracts of Argemonemexicana leaves on the development of Corcyra Cephalonica (Stainton) for the protection of the stored grains. 3( 4): 20-22

Korunic, Z. (1998). Diatomaceous earths, a group of natural insecticides. J. Stored Prod. Res., 34 : 87-97

Kumavat, K. C. (2009). Efficacy of plant products against lesser grain borer, Rhyzoperthadominica (Fabricius) in stored wheat, Triticumaestivum (Linnaeus). J. Insect Sci., 22(4) :448-452

Mahgoub, S. M. and Mawaheb, M. Z. (2014). Field and laboratory assessment of the efficacy of some inert dusts against some stored grain insects, Egypt J. Agri. Res., 92 (1): $1-8$

Mishra, R. C. and Pandey, R. K. 2014. Efficacy of different insecticides against Sitophilus oryzae Linn. in stored wheat seed .Int. J. of Biores. Stress Managt., 5(3):404408

Nadra, H. A. M., (2006). Use of Sesbaniasesban (L.) Merr seed extracts for the protection of wheat grain against the granary weevil, Sitophilus granarius (L.) (Coleoptera: Curculionidae). Scientific Journal of King Faisal University. Basic Appl. Sci., 7: 121-135

Onu, F. M.., E. Ogu and M. E. Ikehi. (2015). Use of neem and garlic dried plant powders for Controlling some stored grains pests. Egypt J. Biol. Pest Cont., 25(2):507 $-512$

Rajapakse, R. H. S. (2006). The potential of plants and plant products in stored insect pest management. The $J$. Agri. Sci., 2: 11-21

Rajashekar Y., Gunasekaran N., Shivanandappa T. (2010). Insecticidal activity of the root extract of Decalepishamiltonii against stored product insect pests and its application in grain protection. J. Food Sci. Tech., 47: 310-314

Samyal, A. and Sharma, R. K. (2006). Plant material as seed protectant against lesser grain borer, Rhizoperthadominica (Fab.) and khapra beetle, Trogodermagranarium Everts. Ind. J. App. Entomol., 20 (2) : 121-124

Shanmugapriyan, R. and Dhanalakshmi, V. (2015). Biological effects of neem on the pupation of Henosepila chnavigintiocto punctata Fab. on bitter gourd. J. Entomol. Zool.Studies, 3 (1): 78-81

Subramanyam, B. and Hagstrum, D. W. (1995). Resistance measurement and management of Insect in Stored Products. In: eds. Subramanyam B. and Hagstrum D.W., Marcel Dekker. New York Pp 331-397

Upadhyay, R. K. and Ahmad, S. 2011. Management Strategies for Control of Stored Grain Insect Pests in Farmer Stores and Public Ware Houses. World J. Agri. Sci., Gorakhpur University, 7(5): 527-549

Verma, S. P., Singh, B. and Singh, Y. P. (1983). Studies on the comparative efficacy of certain grain protectants against Sitotrogacerealella (Oliver.), Bull. of Grain 